\title{
Cloning and Functional Characterization of Two Key Enzymes of Glycosphingolipid Biosynthesis in the Amphibian Xenopus laevis
}

\author{
Melchor E. Luque, ${ }^{1}$ Pilar M. Crespo, ${ }^{2}$ María E. Mónaco, ${ }^{1}$ Manuel J. Aybar, ${ }^{1}$ José L. Daniotti, ${ }^{2}$ and \\ Sara S. Sánchez ${ }^{1 *}$
}

\begin{abstract}
Gangliosides are a subfamily of complex glycosphingolipids (GSLs) with important roles in many biological processes. In this study, we report the cDNA cloning, functional characterization, and the spatial and temporal expression of Xlcgt and Xlgd synthase during Xenopus laevis development. Xlcgt was expressed both maternally and zigotically persisting at least until stage 35. Maternal Xlgd3 synthase mRNA could not be detected and showed a steady-state expression from gastrula to late tailbud stage. Xlcgt is mainly present in involuted paraxial mesoderm, neural folds, and their derivatives. Xlgd3 synthase transcripts were detected in the dorsal blastoporal lip, in the presumptive neuroectoderm, and later in the head region, branchial arches, otic and optic primordia. We determined the effect of glycosphingolipid depletion with 1-phenyl-2-palmitoyl-3-morpholino-1-propanol (PPMP) in mesodermal layer. PPMP-injected embryos showed altered expression domains in the mesodermal markers. Our results suggest that GSL are involved in convergent-extension movements during early development in Xenopus. Developmental Dynamics 237: 112-123, 2008. ๑ 2007 Wiley-Liss, Inc.
\end{abstract}

Key words: amphibian; glycosphingolipids; mesodermal layer

Accepted 7 November 2007

\section{INTRODUCTION}

Gangliosides are a subfamily of complex glycosphingolipids (GSLs) that contain one or more residues of sialic acid and are ubiquitous components of eukaryotic cell membranes. They are amphipathic molecules composed of the hydrophobic lipid moiety of ceramide, embedded in the outer leaflet of the membrane, and a hydrophilic group of oligosaccharide chains with variable length and complexity exposed to the outer environment
(Kolter et al., 2002; Degroote et al., 2004).

Ganglioside biosynthesis begins in the membranes of the endoplasmic reticulum with the formation of ceramide, the membrane anchor of GSLs. After transference to the Golgi apparatus, ceramide is modified by the action of UDP-glucose:ceramide glucosyltransferase (EC 2.4.1.80, GlcT-1). This enzyme catalyzes the first biosynthetic step for the vast majority of GSLs and the resulting glucosylcer- amide is subsequently modified by a series of glycosltransferases to produce several GSL families. Different sialyltransferases build up the gangliosides GM3, GD3, and GT3. Ganglioside GD3 synthase, an $\alpha$ 2,8-sialyltransferase (EC 2.4.99.8, ST8Sia 1), is a key enzyme for the synthesis of whole b-series gangliosides (Allende and Proia, 2002).

UDP-glucose:ceramide glucosyltransferase (CGT) was originally found by Basu et al. (1968) in embryonic

${ }^{1}$ CONICET, UNT, INSIBIO, Departamento de Biología del Desarrollo, San Miguel de Tucumán, Argentina

${ }^{2}$ CONICET, UNC, CIQUIBIC, Departamento de Química Biológica, San Miguel de Tucumán, Córdoba, Argentina

Grant sponsor: Consejo Nacional de Investigaciones Científicas y Técnicas (CONICET); Grant sponsor: CIUNT; Grant sponsor: Secretaría de Ciencia y Tecnologíía, Universidad Nacional de Córdoba; CONICET; Grant sponsor: Agencia Nacional de Promoción Científica y Tecnológica (FONCYT), Argentina.

*Correspondence to: Sara S. Sánchez, CONICET, UNT-INSIBIO, Departamento de Biología del Desarrollo, Chacabuco 461, San Miguel de Tucumán (T4000ILI), Argentina. E-mail: ssanchez@fbqf.unt.edu.ar

DOI 10.1002/dvdy.21406

Published online 18 December 2007 in Wiley InterScience (www.interscience.wiley.com) 
chicken brain and was partially purified from rat liver Golgi membranes (Durieux et al., 1990). The cloning of human and mouse ceramide glucosyltransferases provided a novel tool for the study of the biological roles of GSLs (Ichikawa et al., 1996). These molecules are believed to play significant roles in a variety of cell membrane events including cell interactions, signaling, trafficking, and sorting (Hakomori, 1990, 2004; Hidari et al., 1996; Simons and Toomre, 2001; Hakomori and Handa, 2003). The expression of glycosyltransferases, which is tissue- and cell-specific, is higly regulated during differentiation and proliferation ( $\mathrm{Ji}$ et al., 1999).

The role of GSLs in development and differentiation was studied by Yamashita et al. (1999), who demonstrated that GSL synthesis is essential for mice embryonic development as well as for the differentiation of certain tissues.

In previous work dealing with amphibian embryogenesis, we determined the participation of the GM1 ganglioside in Bufo arenarum gastrulation. The results showed that this ganglioside is differentially expressed by embryonic cells and is essential for the morphogenetic processes of the mesodermal layer (Aybar et al., 2000a,b). A differential distribution of ganglioside GM1 and sulphatide was demonstrated during the development of Xenopus embryos (Kubo et al., 1995).

The activities of glycosyltransferases and sialidases during the early development of Xenopus, analyzed by Gornati et al. $(1995,1997)$, showed the highest enzymatic activity during early embryogenesis. Recently, Rimoldi et al. (2007) reported the sequences of two another isoforms of ST8Sia I and their expression during later Xenopus embryogenesis, probably reflecting the pseudotetraploidy in Xenopus laevis.

Although GSLs, which are assumed to be present in amphibian cells, are involved in the involution and convergent-extension movements of mesodermal cells (Aybar et al., 2000b), very little is known at the molecular level about the participation of gangliosides in the complex molecular mechanisms of embryogenesis.

A

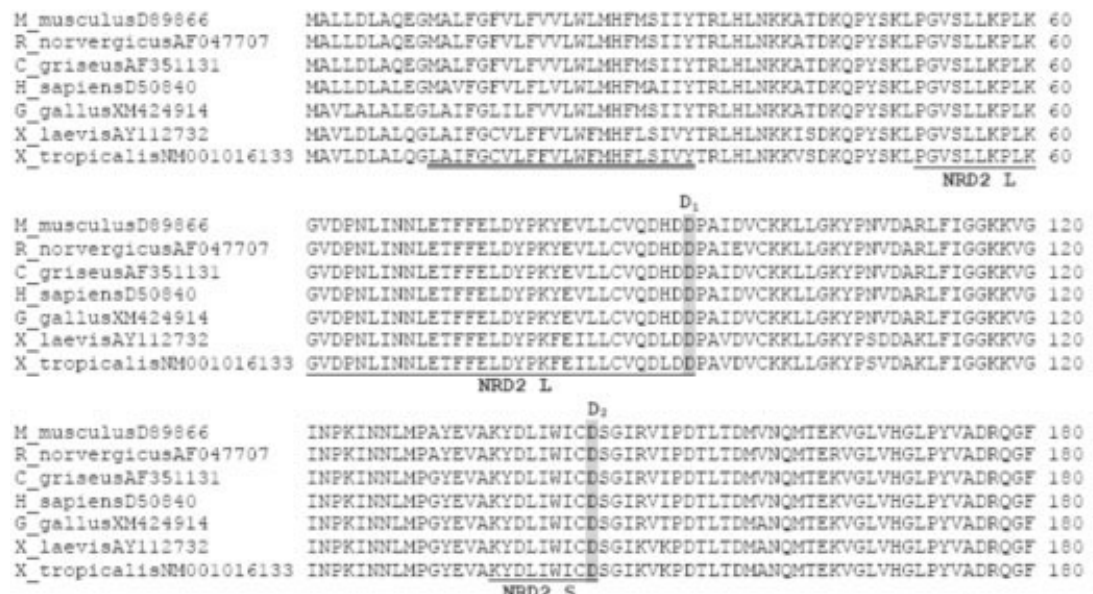

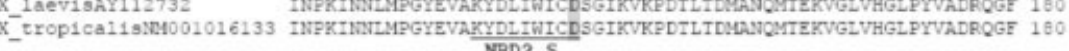

D,

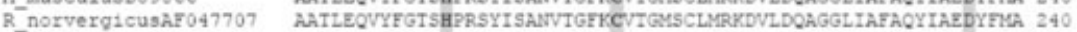

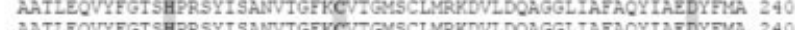

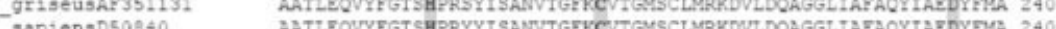

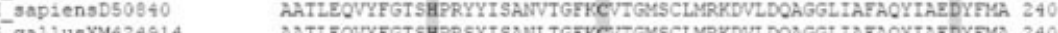
CgallusXM424914 AATLEOVYFGISHPRSYISALIL TGFKCVIGMSCLMRKDVLDOAGGLIAFAOYIAEDYFAG 240 X_LAeVISAY112732 AATLEOVYFGTSHPRSYISANVTGFKCVTGMSCLMRKEVLDOAGGLIAFAOYIAEDYRIA 240

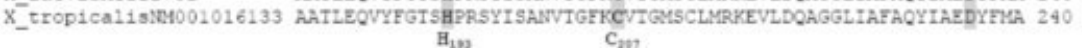

M_musculus De9666

RAIADRGWRF SUSTQVAMOMSGSYSISOFQSRMIRHTKLRIMC.PATIICEPISECFVAS 300

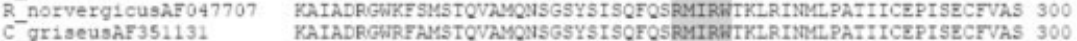

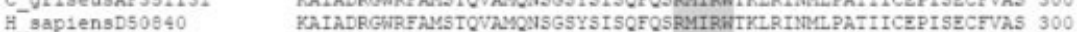

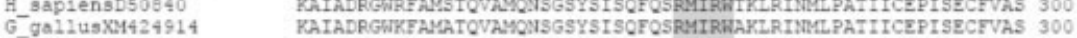

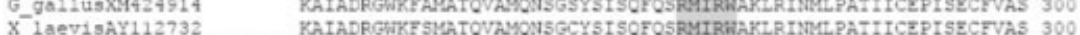

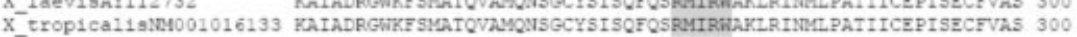
Q/RXXRW

M_musculus De9866 R_norvergicusaF047707 LIIGWAHHVFRDIMVFFCHCLAWFIFDYTQLRGVOGGTLCFSKLDYAVAWFIRESMT 360

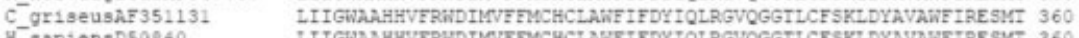
H_-3apiensD50940 CIIGWAAHHVFRWIMVFFCHCLAWFIFDYTOLRGVGGTLCFSKLDYAVAWFTRESMT 360 G_gallusXM424914 LVIGWAMHUVRWDIMFFMCHCLAWFIFDYTQLRGVOGGALCFSKLDYAVAWFIRESUIT 360 X_laev1sAY112732 LIIGWAAHIFRWDIMVFMCHCLAWFIFDYTQLRGVOGGPIMFSKLDYAVAWEIRESMI 360

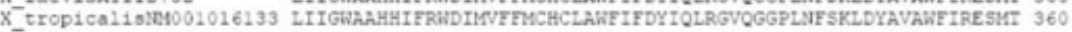

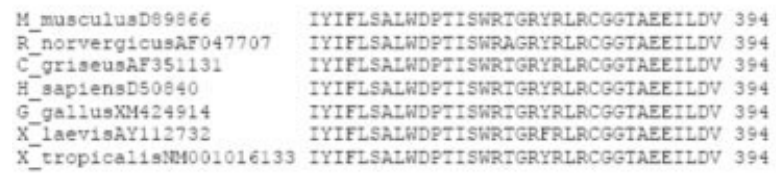

B

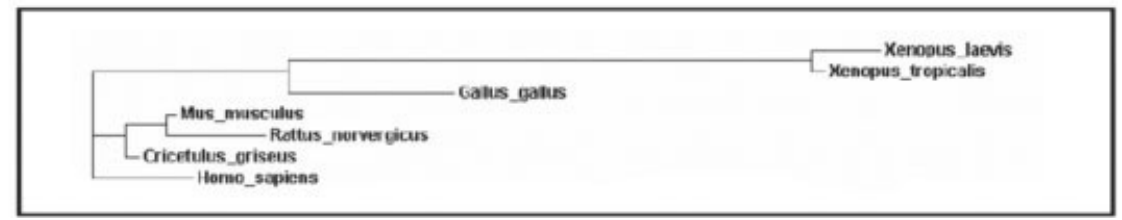

Fig. 1. Comparison of the deduced amino acid sequence of XLCGT with ceramide glucosyltransferases of different species. A: ClustalX alignment of ceramide glucosyltransferases. Putative signalanchor sequence is double underlined and hypothetical "nucleotide recognition domains" (NRD2L and NRD2S) are underlined. The positions of $\mathrm{His}_{193}$ and $\mathrm{Cys}_{207}$ are indicated in bold characters and the positions of amino acids in the $D_{1}, D_{2}, D_{3}, Q / R X X R W$ motifs are shaded in gray. B: Phylogenetic tree of M. musculus D89866, R. norvergicus AF047707, C. griseus AF351131, H. sapiens D50840, G. gallus XM424914, X. tropicalis NM001016133, and X. laevis AY112732 ceramide glucosyltransferases. The tree was produced using the ClustalW program based on amino-acid sequences.

In this study, we report the cDNA cloning of Xlcgt and Xlgd3 synthase and the spatial and temporal expression of mRNA of these two key en- zymes during early and late frog development. In order to provide functional evidence of the two cloned Xenopus glycosyltransferases, we an- 
alyzed their in vivo expression and evaluated the catalytic activities for glycolipid substrates and sugar donors. Moreover, we also performed an extensive analysis of subcellular distribution of XLCGT and $\mathrm{XLGD}_{3}$ synthase in Chinese hamster ovary (CHO)-K1 and Madin-Darby canine kidney epithelial (MDCK) cells. We used 1-phenyl-2-palmitoyl-3-morpholino-1-propanol (PPMP), a GSL biosynthesis inhibitor, to provide a deeper insight into the role of gangliosides in mesodermal cell behavior by examining the expression of mesodermal molecular markers.

\section{RESULTS AND DISCUSSION}

\section{Isolation of $X$. laevis cgt and gd3 synthase Homologue}

By performing a homology search through the EST databases at NCBI using the human cgt cDNA sequence (accession no. D50840) and mouse gd3 synthase cDNA sequence (accession no. NM_011374), we identified a Xlcgt and Xlgd3 synthase homologue, respectively. The complete sequences, which were deposited in the GenBank (accession no. AY112732 and EF067919), revealed that they encoded the entire open reading frame of 446 amino acids for the XLCGT protein and 328 amino acids for the $\mathrm{XLGD}_{3}$ synthase protein.

The deduced XLCGT amino acid sequence displays the predicted features of a glycosyltransferase protein belonging to the glycosyltransferase family 21 (Campbell et al., 1997; Wu et al., 1999). The same family has also been described as group 9 of the $\mathrm{NRD}_{2}$ glycosyltransferases, which were grouped according to different types of "nucleotide recognition domains" (NRDs) (Kapitonov and Yu, 1999). Figure 1A shows a ClustalX alignment of glucosylceramide synthases where the putative N-terminal transmembrane domain is doubly underlined and hypothetical $\mathrm{NRD}_{2} \mathrm{~L}$ and $\mathrm{NRD}_{2} \mathrm{~S}$ are underlined (Kapitonov and $\mathrm{Yu}, 1999)$. In addition, we showed the presence of the $D_{1}, D_{2}, D_{3}(Q / R)$ XXRW putative active site motifs present in the region flanking His-193 and Cys-207 (Wu et al., 1999; Marks et al., 2001). Site-directed mutagenesis of glucosylceramide synthase at those highly conserved residues

A
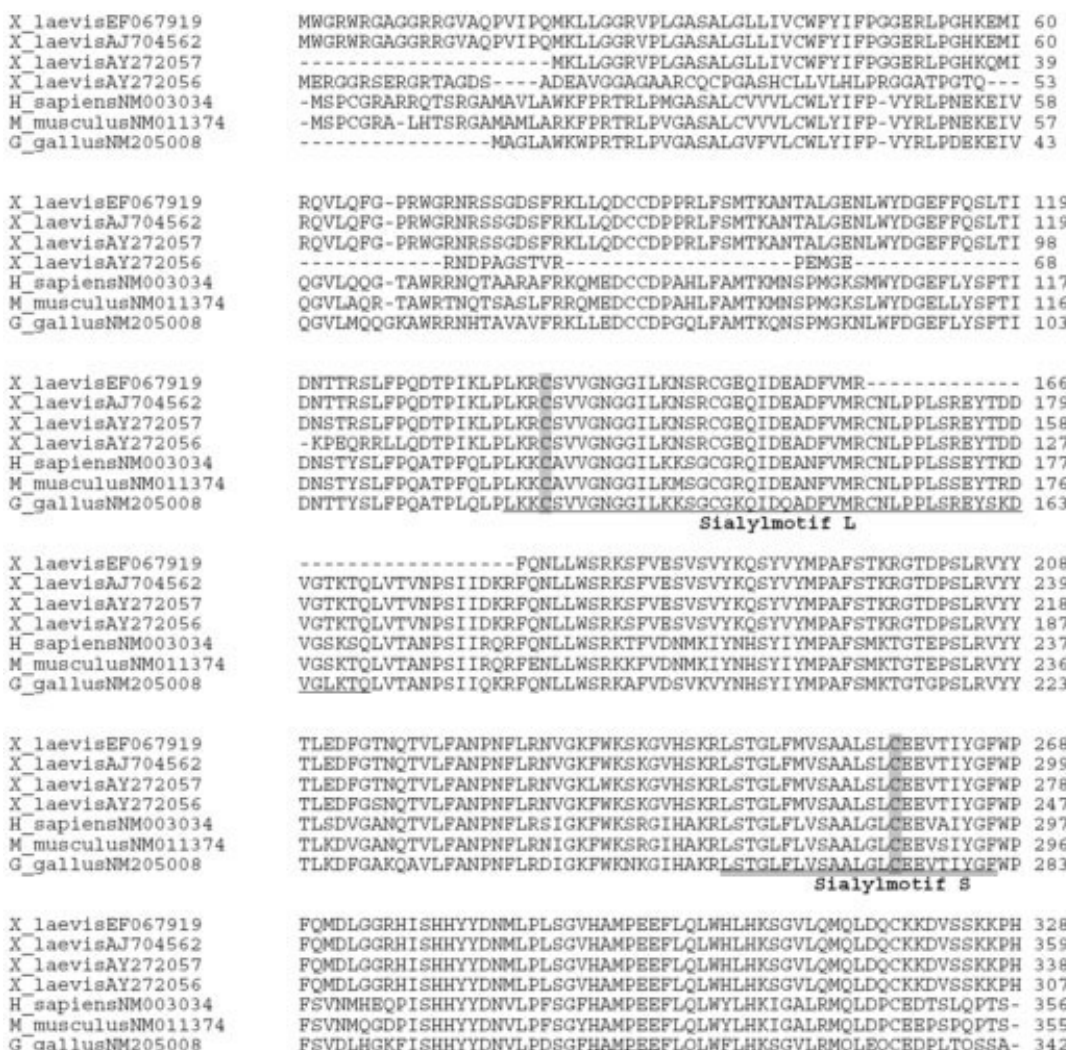

-MSPCGRA- LETSRGAMAMLARKFPRTRLPUGASALCVYYLCGLYIFP-VYRLPNBKEIV 58 MAGLAKKWPRTRLPYGASALGVFYLCWLYIFP-VYRLPDEKEIV 43

RQVLOFG-PRWGRNRSSGDSFRKLLQDCCDPPRLFSMTKANTALGENLWYDGEFFQSLTI 119 RQVLOFG-PRWGRNRSSGDSFRKLLODCCDPPRLFSMTKANTALGENLWYDGEFFOSLTI 119 RQVLQFG-PRWGRNRSSGDSFRKLLDCCDPPRLFSMTKANTALGENLWYDGEFFQSLTI 98 QGVLOQG-TAWRRNQTAARAFRKQMEDCCDPAHLFAMTKNSPMGKSMWYDGEFLYSFTI 117 QGVLAQR - TAWRTNQTSASLFRRQMEDCCDPAHLFAMTKNNSPNGKSLWYDGELLYSFTI 116 QGVLMQQGKAWRRNHTAVAVFRKLEDCCDPGQLFAMTKQNSPMGKKLWFDGEFLYSFTI 103

DNTTRSLFPQDTPIKLPLKKCSVVGIGGI LKASRCGEQIDEADFVMR _... . . . . . 166 DNTTRSLFPODTDIKLPLKRC CVVGNGGILINSRCGEQIDEADFWMRCALDPLLSREYTDD 17 DNSTRSLPPQDTPIKLPLKRC SVVGNGGILKNSRCGEQIDEADFVMRCNLD PLSRBYTDD 158 - KPEQRRLLODTPI KLPLKRCSVVGNGGILKNSROGEQIDBADFVMRCILPPLSREYTDD 127 DNSTYSLFPOATPFOLPLKKCAVVGNGGILKMSGCGROIDEANFVMRCNLPPLSSEYTRD 176 DNTTYSLFPQATPLQLPLKKCSVVGNGGILKKSGCGKOTDQADFVMRCNLPPLSRBYSKD 163 Sialylmotif L

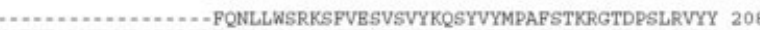
VGTKTQLVTVNPS IDKRFONLLWSRKSFVESVSVYKQSYVYMPAFSTKRGTDPSLRVYY 239 VGTKTQLVTVNPSI IDKRFENLLWSRKSFVESVSVYKOSYVYMPAFSTKRGTDPSLRVYY 218 VGTKTQLVTVNPSI IDKRFQNLLWSRKSFVESVSVYKQSYVYMPAFSTKRGTDPSLRVYY 187 VGSKSQLVTANPSI IRQRFQNLLWSRKTFVDNMKIYNHSYI YMPAFSMKTGTEPSLRVYY 237

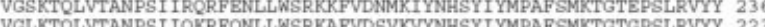

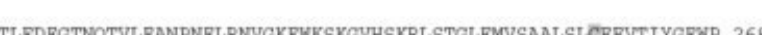
TLEDFGTNOTVLFANPAPL,PNYGKFWKSKCVHSKRLSTGLFMVSALLSLCBEVTIYGFWP 296 TLEDFGTNOTVLFANPNEL.RNVGKL KKSKGVHSKRLSTGLFMVSAALSL CREVTIYGENP 29 TLEDFGSNOTVLPANPNFLRNVGKFWKSKGVHSKRLSTGLFMVSAALSLCBEVTIYGFWP 247 TLSDVGANQTVLPANPNFLRSIGKFWKSRGIHAKRLSTGLFLVSAALGLCEBVAIYGFWP 297

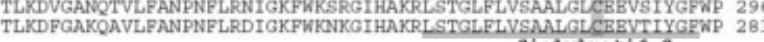
sialyimotit $\mathrm{s}$

FQMDLGGRHISHHYYDNMLPLSGVHAMPEEFLQLWHLHKSGVLQMQLDQCKKDVSSKKPH 328 FQMDLGGRHI SHHYYDNMLPLSGVHAMPBEFLOLWHLHKSGVLOMQLDQCKKDVSSKKPH 35 FQMDLGGRHISHHYYDMMLDLSGVHAMPEEFLOLWHLHKSGVLQMQLDQCKKDVSSKKPH 338 FQMLLGGRAISHAYM FSVIMBOPPT FSVMQCDPISHAYNTH Sialyimotif III Sialyimotif vs

B

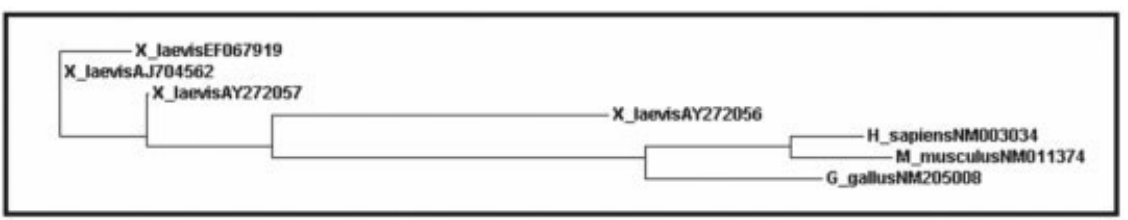

Fig. 2. Comparison of the deduced amino acid sequence of XLGD3 synthase with $\alpha 2,8$ sialyltransferases of different species. A: ClustalX alignment of $\alpha 2,8$-sialyltransferases. Sialylmotifs L (large), S (small), motif III, and VS (very small) are underlined, double underlined, dashed underlined, and dotted underlined, respectively. The conserved cysteine residues in the $L$ and $S$ sialylmotifs are shaded in gray. B: Phylogenetic tree of X. laevis AJ704562, X. laevis AY272057, X. laevis AY272056, M. musculus NM011374, H. sapiens NM003034, and G. gallus NM205008 GD $_{3}$ synthases. The tree was produced using the ClustalW program based on deduced amino-acid sequences.

showed that almost all of them were essential for the glucosylceramide synthase activity and represent a common substrate-binding and/catalytic region in this enzyme (Wu et al., 1999; Marks et al., 2001). When we compared the entire amino acid sequence, we found that XLCGT shares a high identity percentage $(>90 \%)$ with the other glucosylceramide synthases studied.

We found four well-conserved motifs for the $\mathrm{XLGD}_{3}$ synthase protein: $\mathrm{L}$ (large), S (small) motif III, and VS (very small) (Fig. 2A). These residues have a structural or a functional role and are common to all sialyltransferases (Harduin-Lepers et al., 2005). The $\mathrm{XLGD}_{3}$ synthase predicted protein shared between 86 and $91 \%$ identity with other $X$. laevis $\alpha 2,8$-sialyltransferases reported: accession no. AJ704562 (91\%), AY272057 (89\%), and AY272056 (86\%) and 65, 61, and $60 \%$ identity with $\mathrm{GD}_{3}$ synthase homologues from chicken, human, and mouse, respectively (Fig. 2A). 
The phylogenetic trees of both cloned enzymes, where branch lengths are proportional to the amount of inferred evolutionary change, clearly indicate that XLCGT and $\mathrm{XLGD}_{3}$ synthase are closely related to the homologue and orthologue proteins studied (Figs. 1B and 2B).

The characterization of the glucosylceramide synthase gene knockout mice showed that homozygosity for the disruption of this gene caused embryonic lethality in gastrulation stage embryos with intense apoptosis in the ectodermal layer. The results proved that the GSL synthesis pathway driven by glucosylceramide synthase is required for mouse embryonic development (Yamashita et al., 1999).

The elimination of $b$-series gangliosides by disruption of the GD3S gene encoding $\mathrm{GD}_{3}$ synthase yields mice without any apparent major neurological abnormalities (Kawai et al., 2001; Okada et al., 2002; Inoue et al., 2002). However, these mice do show impaired regeneration of the hypoglossal nerve after lesion (Okada et al., 2002). Strikingly, GalNaAcT and GD3S double knockout mice present a very severe phenotype, illustrating the fundamental importance of gangliosides

Fig. 3. Biochemical and cellular characterization of XLCGT and $\mathrm{XLGD}_{3}$ synthases. $\mathrm{A}$ : $\mathrm{CHO}-\mathrm{K} 1$ cells transiently expressing Xlcgt were immunostained with antibody to $\mathrm{HA}$ (red) and examined by the intrinsic fluorescence of YFP from Sial-T2-YFP, a Golgi marker (pseudocolored green) or lip33-YFP, a endoplasmic reticulum (ER) marker (pseudocolored green). Merge, overlap of both XLCGT and marker signals (orange-yellow). B: XLCGT catalyze the formation of glucosylceramide. TLC analysis was carried out with cell lysates. Lane 1: Mock transfected wild-type CHO-K1 cells. The enzymatic reaction was stopped at $t=0$; Lanes 2 and 3: Mock transfected wild-type $\mathrm{CHO}-\mathrm{K} 1$ cells (60 min of incubation). Lanes 4 and 5 : Transiently transfected $\mathrm{CHO}-\mathrm{K} 1$ cells expressing XLCGT (60 min of incubation). Cer, ceramide; GlcCer, glucosylceramide; SM, sphingomyelin. C: $\mathrm{CHO}-\mathrm{K} 1$ cells transiently expressing $\mathrm{XLGD}_{3}$ synthase were immunostained with antibody to HA (red) and examined by the intrinsic fluorescence of YFP from SialT2-YFP, a Golgi maker (pseudocolored green) or lip33-YFP, an endoplasmic reticulum (ER) marker (pseudocolored green). Merge, overlap of both $\mathrm{XLGD}_{3}$ synthase and marker signals (orange-yellow). Single confocal sections were taken every $0.7 \mu \mathrm{m}$ parallel to the coverslip. Images are representative of the majority of the observed transfected cells. Scale bar $=10 \mu \mathrm{m}$.
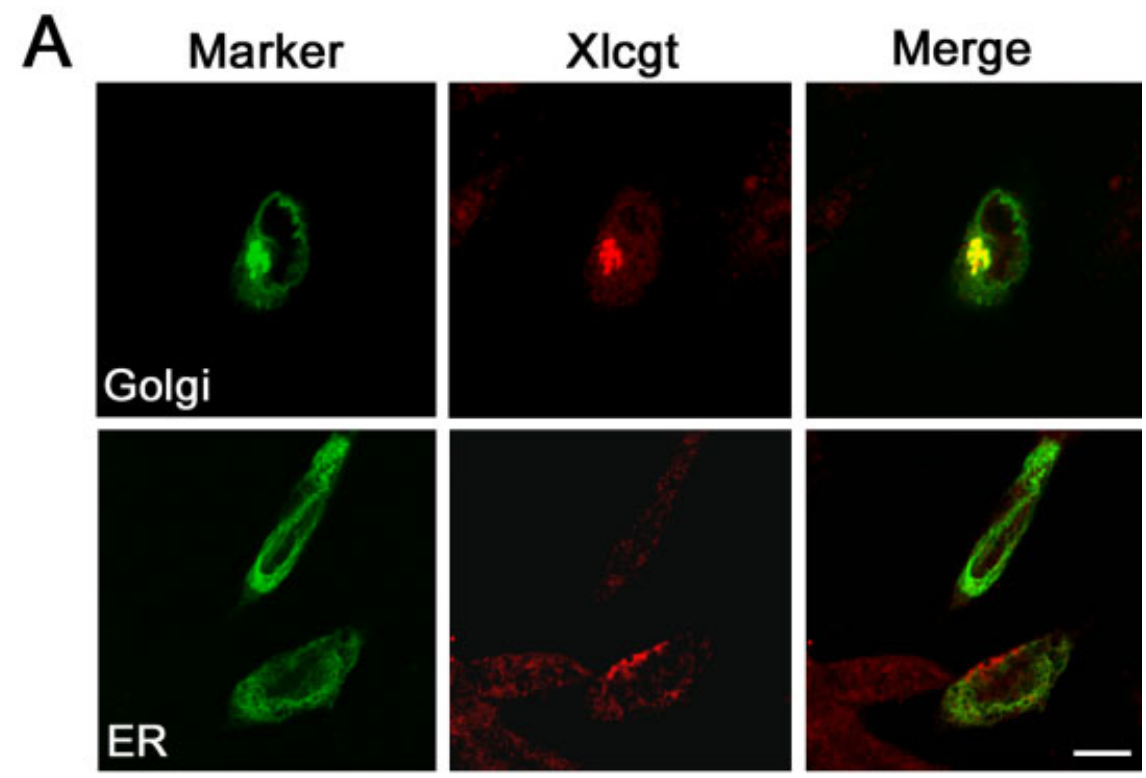

B
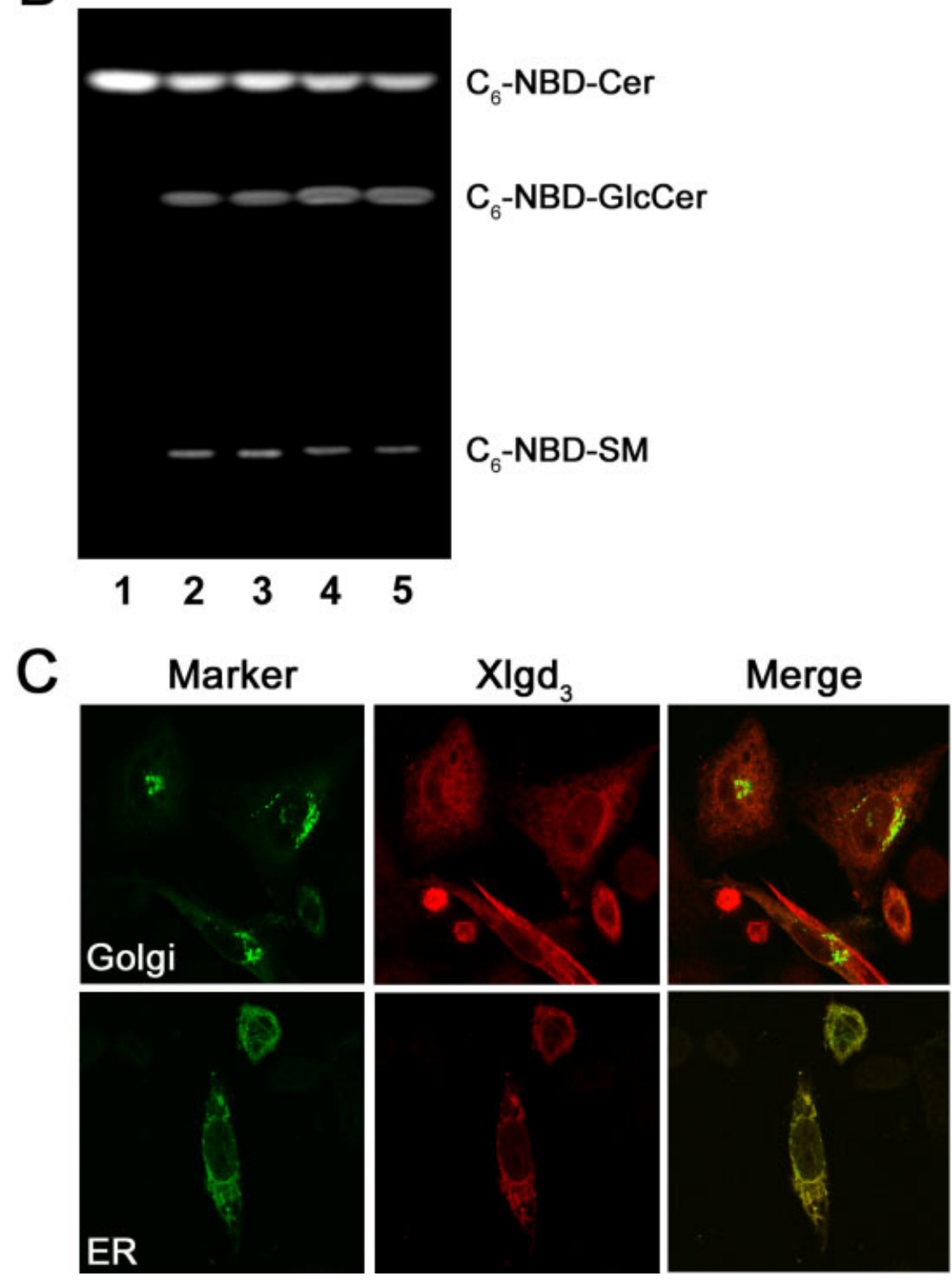

Fig. 3. 
in the function of the nervous system (Kawai et al., 2001).

The similarity of the amino acid sequences and conserved motifs evidenced in XLCGT and $\mathrm{XLGD}_{3}$ synthase to those in other vertebrates could suggest that their functions are also conserved throughout evolution.

\section{Characterization of Xenopus laevis XLCGT and $\mathrm{XLGD}_{3}$ Synthase}

To characterize the protein product of Xenopus laevis Xlcgt cDNA, the plasmid pCEFL-Xlcgt-HA was generated. This plasmid directs the expression of Xenopus laevis XLCGT tagged with a 9-amino acid antigenic epitope from the viral $\mathrm{HA}$ at its $\mathrm{C}$-terminus. Subcellular localization of the tagged $\mathrm{Xe}$ nopus laevis XLCGT was examined in transfected CHO-K1 cells. XLCGT-HA was detected predominantly in a juxtanuclear zone, in a pattern of staining typical of the Golgi apparatus (Fig. 3A). To confirm that the expressed protein was sorted to this organelle, cells were double transfected to express XLCGT-HA and Sial-T2YFP, a medial Golgi resident protein (Giraudo and Maccioni, 2003). Confocal immunofluorescence microscopy analysis revealed a clear colocalization between XLCGT and Sial-T2YFP, thus confirming the Golgi complex localization of Xenopus laevis CGT. On the other hand, no colocalization was observed between the major histocompatability complex class II invariant chain isoform lip33 fused to YFP (Iip33-YFP), the endoplasmic reticulum marker, and Xenopus laevis CGT. A similar subcellular distribution of XLCGT was also observed in MDCK cells (results not shown). To determine whether Xenopus laevis CGT is enzymatically capable of generating glucosylceramide, lysates from CHO-K1 cells transiently expressing XLCGT were assayed in vitro for glucosylceramide synthetic activity using C6-NBD-Ceramide as acceptor and UDP-glucose as donor (Fig. 3B). Homogenates from transfected CHO-K1 cells showed XLCGT activity values $60 \%$ higher than homogenates from mock transfected wild type cells. It should be noted that the specific activity of XLCGT in the transient transfectants could be 10 -fold higher if an efficiency of transfection of $10 \%$ is considered. Extracts from XLCGT transfected CHO-K1 cells analyzed by Western blotting showed XLCGT migrating in SDS-PAGE with the expected molecular mass of $\sim 45,700 \mathrm{Da}$ (results not shown). Taken together, these results indicate that the isolated cDNA coding for the Xenopus laevis CGT directs the synthesis of an enzymatically active protein that carries the molecular signals responsible for its proper sorting to the Golgi apparatus of CHO-K1 and MDCK transfected cells, as previously reported (Coste et al., 1986; Jeckel et al., 1992; Kohyama-Koganeya et al., 2004).

By performing a homology search through the EST databases at the NCBI using the mouse gd3 synthase cDNA sequence, we identified a $\mathrm{Xlgd3}$ synthase homologue clone (BJ032650). The complete sequencing of this clone reveals the lack of the typical $5^{\prime}$ sequence coding for the first 71 amino acids bearing the stem region, the transmembrane domai, and the short cytosolic amino terminus. To characterize the protein product of $\mathrm{Xlgd3}$ synthase cDNA and to determine its subcellular localization, the $\mathrm{pH}-\mathrm{Xlgd} 3$ synthase-HA vector was generated. This plasmid directs the expression of $\mathrm{XLGD}_{3}$ synthase (257 amino acids containing the putative catalytic domain) tagged both with a 9-amino acid antigenic epitope from the viral $\mathrm{HA}$ at its C-terminus and the first 57 amino acids from human $\mathrm{GD}_{3}$ synthase at the $\mathrm{N}$-terminus. In order to characterize the subcellular distribution of epitope-tagged $\mathrm{XLGD}_{3}$ synthase (XLGD ${ }_{3}$ synthase-HA), we performed extensive colocalization analyses with organelle markers in $\mathrm{CHO}-\mathrm{K} 1$ cells (Fig. 3C). XLGD 3 synthase-HA was found predominantly located with a reticular pattern colocalizing with Iip33-YFP, a recognized endoplasmic reticulum marker. $\mathrm{XLGD}_{3}$ synthase-HA was also found colocalizing partially with Sial-T2-YFP, a medial Golgi resident protein in $\mathrm{CHO}-\mathrm{K} 1$ cells. Extracts from $\mathrm{XLGD}_{3}$ synthaseHA-transfected $\mathrm{CHO}-\mathrm{K} 1$ cells analyzed by Western blotting with anti-HA antibody showed $\mathrm{XLGD}_{3}$ synthase migrating in SDS-PAGE with the expected molecular mass of $\sim 44,380 \mathrm{Da}$, corresponding to the molecular mass predicted from the cDNA sequence plus three N-linked oligosaccharides (Martina et al., 1998). However, other bands that probably correspond to partially N-glycosylated $\mathrm{XLGD}_{3}$ synthase-HA were also observed (results not shown). Finally, homogenates from transiently transfected CHO-K1 cells did not show an appreciable $\mathrm{XLGD}_{3}$ synthase-HA enzyme activity in contrast with extracts from the same cells stably transfected with the chick $\mathrm{GD}_{3}$ synthase cDNA (results not shown). The relatively high proportion of $\mathrm{XLGD}_{3}$ synthase-HA detected in the endoplasmic reticulum and the lack of enzyme activity could be a consequence of the impaired N-glycosylation, as previously reported for chick $\mathrm{GD}_{3}$ synthase expressed in cells exposed to inhibitors of N-glycosylation (Martina et al., 1998). We should also consider that the frog Xenopus laevis presents a pseudotetraploid genome. Hence, duplicate genes can differ substantially in expression levels and patterns. Therefore, our results are consistent with the subfunctionalization model for retention of duplicated genes, in which paralogs acquire complementary coding and/or cis-regulatory mutations (Hellsten et al., 2007).

\section{Xlcgt and $\mathrm{Xlgd}_{3}$ synthase Temporal and Spatial Expression Patterns}

In order to study the developmental gene expression of the $X l \lg t$ and $X l g d_{3}$ synthase, we analyzed total RNA isolated by RT-PCR from oocytes and embryos at different stages.

$X l c g t$ was expressed both maternally (Fig. 4A) and zygotically (Fig. 4B) Xlcgt transcripts were detected at all stages of oogenesis with the exception of previtellogenic oocytes (Fig. 4A). In agreement with our results, Hidari et al. (1991) reported that monosialosylgangliopentaosyl (GalNAc-GM1b), a downstream product within the ganglioside biosynthetic pathway, was a major ganglioside in $X$. laevis oocytes.

During embryogenesis, Xlcgt mRNA was weakly observed as early as in the one-cell stage, shortly after fertilization, and remained at a relatively uniform level throughout embryogenesis (Fig. 4B), persisting at least until stage 35 . 


\section{A I-II III IV $v$ v

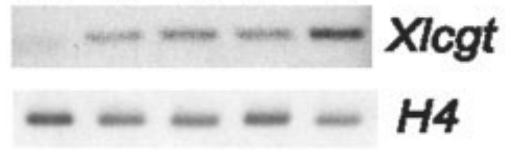

B

$\begin{array}{llllllll}1 & 7 & 12 & 15 & 19 & 22 & 25 & 35\end{array}$

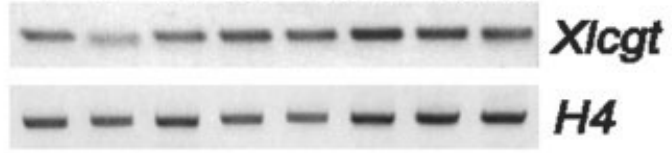

C $\begin{array}{lllllllll}11 & 13 & 15 & 17 & 19 & 22 & 25 & 29 & 35\end{array}$

XIgd3 synthase

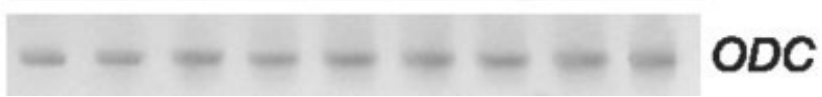

Fig. 4. Temporal expression of Xlcgt and XIgd3 synthase by RT-PCR from total RNA at different stages of Xenopus oogenesis and development. The stage of the oocytes and embryos is indicated above each lane. A: Detection of Xlcgt mRNA during oogenesis. B: RT-PCR analysis revealed that XIcgt mRNA was expressed at all stages tested between 1 and 35. C: XIgd3 synthase transcripts were zygotically detected. Histone H4 and ODC were used as an internal control.

The expression pattern of $X l g d 3$ synthase transcripts was analyzed during $X$. laevis oogenesis and early development. Maternal $\mathrm{Xlg}_{3}$ synthase transcripts could not be detected. The first signal was observed at the beginning of gastrulation and became more evident at stage 12 . The Xlgd3 synthase expression persisted until stage 35 and declined afterwards (Fig. 4C).

Our results are in keeping with the ones reported by Gornati et al. (1995, 1997) concerning the in vitro activities of sialidases and glycosyltransferases during the early development of $X$. laevis. They found that GD3 was the most represented ganglioside during early embryogenesis and that SAT-2 $\left(\mathrm{GD}_{3}\right.$ synthase) had an activity peak at day 4 of development (Gornati et al., 1997). However, a correlation between the in vitro activity of these enzymes and the transcripts analyzed in vivo can only be tentative.

Moreover, Rimoldi et al. (2007) showed the presence of another two ST8Sia I mRNA isoforms during $X e$ nopus development and their tissue distribution in adult animals. In concordance with our results, they found that the ST8Sia I mRNA was detectable at the onset of gastrula- tion evidencing a zygotic gene expression.

Our results are the first detailed molecular analysis of these two key enzymes during the early and late development of $X$. laevis. Understanding the roles of gangliosides in embryological processes requires a clear view of the localization of mRNA ganglioside biosynthesis enzymes. Thus, the spatial expression pattern of Xlcgt and Xlgd3 synthase has been further investigated by whole-mount in situ hybridization.

The expression pattern of Xlcgt was analyzed from the midgastrula (stage 11) to the early tadpole stage (stage 35). No expression was detected at stage 11 by whole-mount in situ hybridization. At the late gastrula stage, $X l c g t$ is weak and ubiquitously expressed (results not shown); as neurulation proceeds (stage 15-16), the region of Xlcgt expression moves toward the dorsal structures: involuted paraxial mesoderm and neural folds (Fig. 5A,B). At the tailbud embryo stage (stage 28), only the notochord was strongly stained (Fig. 5C). Thus, the notochord represents a specific expression domain of this mRNA, as shown in a transversal section (Fig. $5 \mathrm{C}$ inset). At later stages (stage 35 ), the expression pattern was maintained in the notochord and a faint new expression domain in the cephalic region was observed (Fig. 5D).

During early gastrulation, Xlcgt mRNA was expressed ubiquitously as reported by Choo et al. (2001) for mouse. The mouse ceramide glucosyltransferase (GlcT-1) gene contains a CpG-rich domain in its promoter region, suggesting that GlcT-1 could be one of the housekeeping genes (Ichikawa et al., 1998), which would explain its ubiquitousness. Moreover, in Xenopus late embryogenesis, the $X l c g t$ transcripts were localized in the dorsal and anterior structures; as in mice (Choo et al., 2001), this gene would be developmentally regulated.

The notochord Xlcgt expression is interesting given the important role of this tissue as a signaling center. In this regard, the presence of XLCGT, an enzyme that controls the first committed step of GSLs synthesis, suggests the participation of gangliosides regulating regional cell signaling pathways as proposed by Allende and Proia (2002).

The expression pattern of $X l g d 3$ synthase was analyzed in embryos between the midgastrula (stage 11) and the early tadpole stage (stage 35 ). Xlgd3 synthase mRNA was detected both in the dorsal blastoporal lip and in the presumptive neuroectoderm (stage 11) (Fig. 6A). The superficial and deep layers of the dorsal marginal zone (DMZ) expressed the Xlgd3 synthase transcripts, as shown in Figure 6B. During gastrulation, the expression domain remained strongly stained in the involuting mesoderm. At stages 13 and 16, Xlgd3 synthase was expressed in the dorsal structures [neural plate and neural folds (Fig. 6C and E)], and was also strongly expressed in paraxial mesoderm and notochord as shown in transversal sections (Fig. 6D and F). At the initial neural tube and early tailbud stage (stages 19 and 22, respectively), the embryos showed an intense expression localized in the neural tube and notochord (Fig. 6G-J).

At the tadpole stage (stage 35), the Xlgd3 synthase mRNA was detected in the head region, branchial arches, and otic and optic primordia (Fig. 6K). This transcript was also localized in 

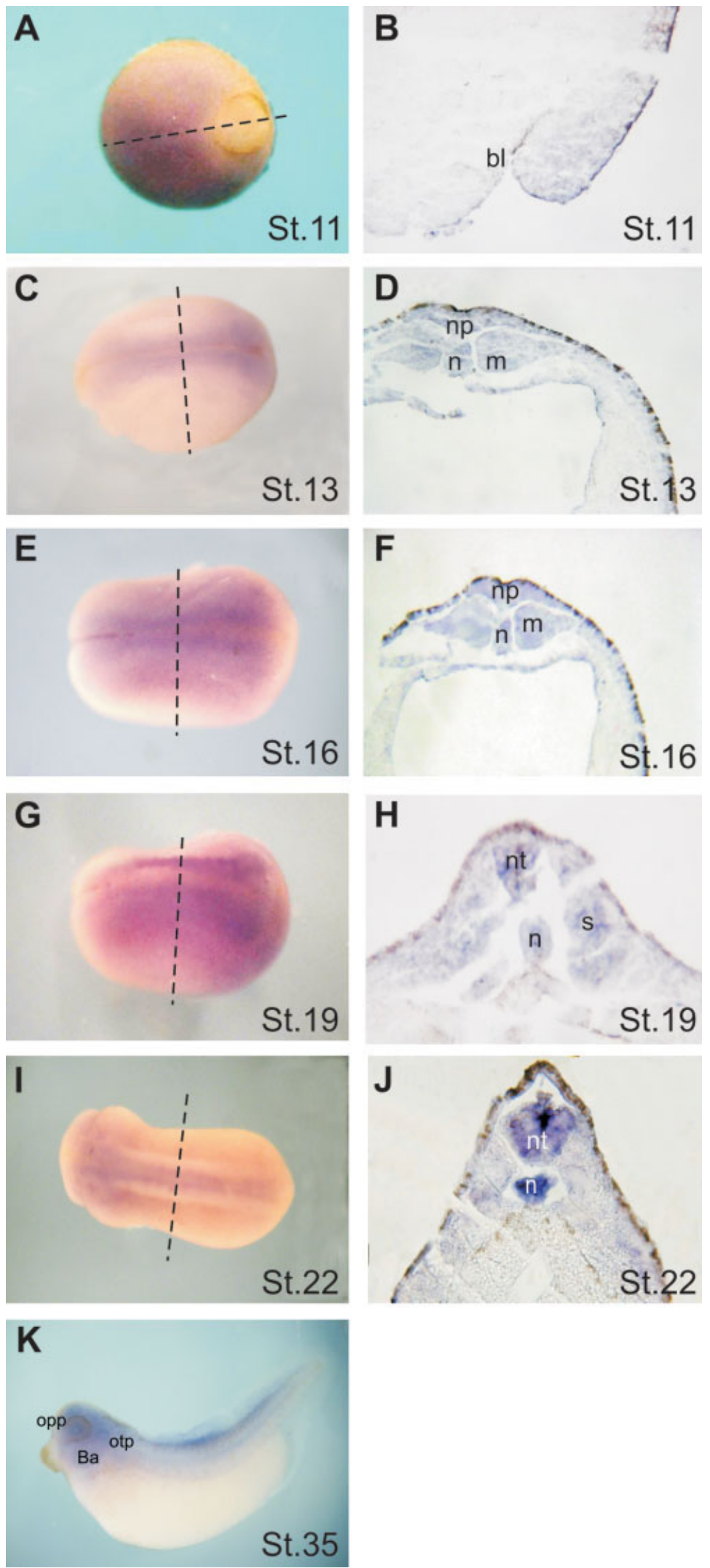

the notochord and was faintly expressed in the somites (Fig. 6K).

This enzyme acts on ganglioside GM3 at the branching point of the ganglioside synthesis pathway where the "a" and "b" families are produced. Our results indicated that Xlgd3 synthase is differently expressed throughout the stages of embryonic development together with the movements of the mesodermal and ectodermal layers and of some of their derivatives.

Finally, our studies of the spatial and temporal expression of the two enzymes studied are important because the transcription and/or stability of the specific mRNA could constitute a level of control of these enzymes and, indirectly, of the ganglioside composition in the developing embryo.

Fig. 6. Expression of the Xlgd3 synthase gene during Xenopus development. NieuwkoopFaber stages of embryogenesis are indicated. A: XIgd3 synthase is faintly expressed in the dorsal mesoderm of stage-11 embryos. B: Histological section showing expression in the dorsal blastopore lip (as indicated in A). C: Stage-13 embryos show expression in dorsal structures (neural plate, notochord, and paraxial mesoderm). D: Transverse section of C. E: Stage-16 embryo. F: Transverse section of E. G: Stage-19 embryo showing expression of GD3s in the neural tube, notochord, and somites. H: Transverse section of G. I,J: In stage-22 embryos, GD3s is strongly expressed in the neural tube and notochord. K: Stage-35 embryos, the $\mathrm{Xlgd}_{3}$ synthase mRNA was detected in the head region, branchial arches, otic and optic primordia. This transcript was also localized in the notochord and was faintly expressed in the somites. bl, blastopore lip; nt, neural tube; n, notochord; s, somites; opp, optic primordium; otp, otic primordium; ba, branchial arches.

Fig. 6. 

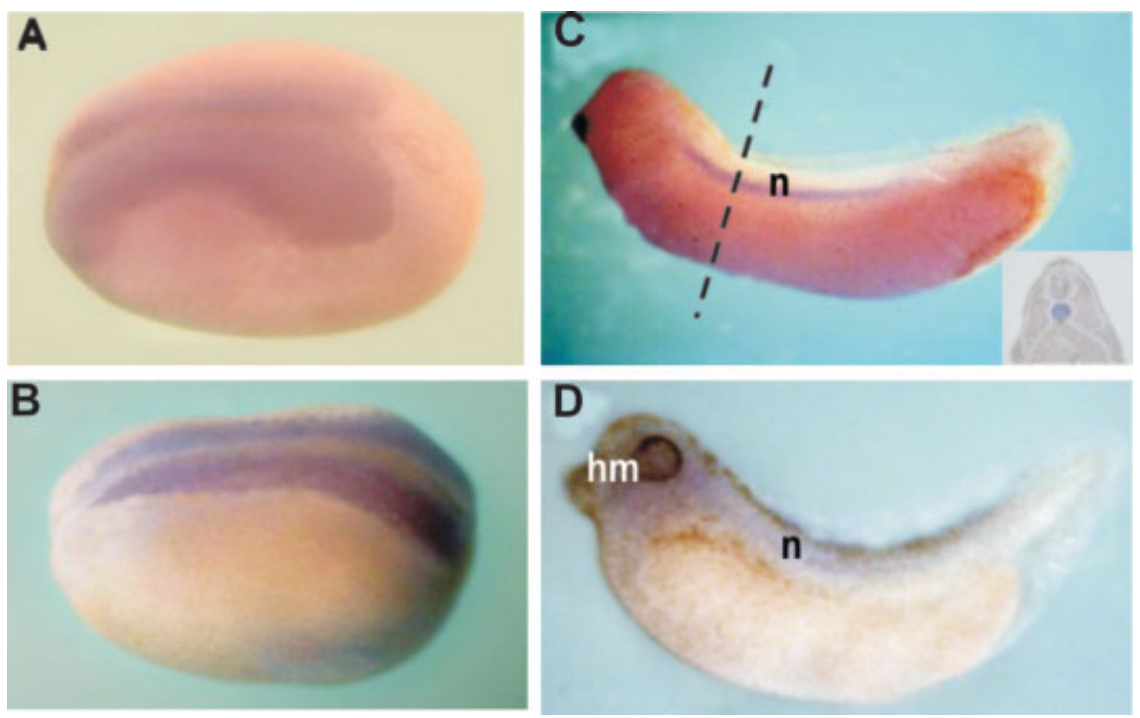

Fig. 5. Expression of Xlcgt during Xenopus development. Nieuwkoop-Faber stages of embryogenesis are indicated. A,B: Xlcgt is expressed in the dorsal structures of stages 15-18 embryos. C: At stages 25-28, Xlcgt is expressed in the notochord. Inset: Transversal section (as indicated in C) shows strong expression in the notochord. D: At later stages (stage 35), the pattern of expression was maintained in the notochord and a faint expression domain was detected in the cephalic region. $\mathrm{n}$, Notochord; hm, head mesoderm.
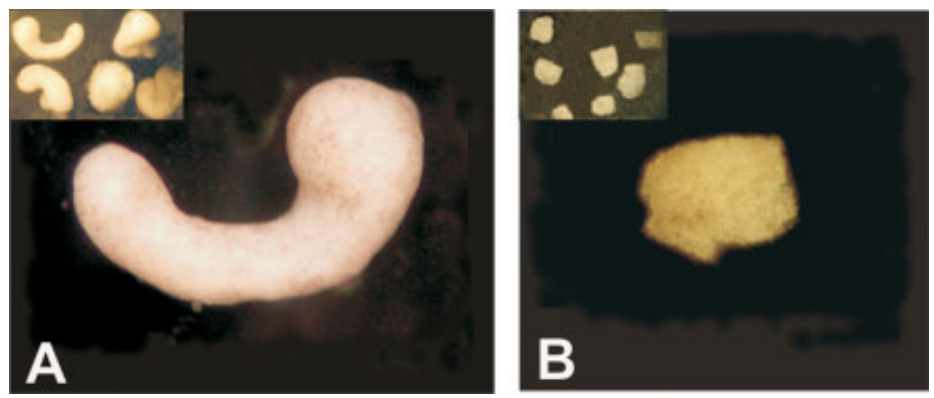

Fig. 7. Effect of PPMP inhibitor on the autonomous convergence-extension movements of sandwich explants. A: Sandwich explants incubated without PPMP solution. B: Sandwich explants incubated with $20 \mu \mathrm{M}$ PPMP solution.
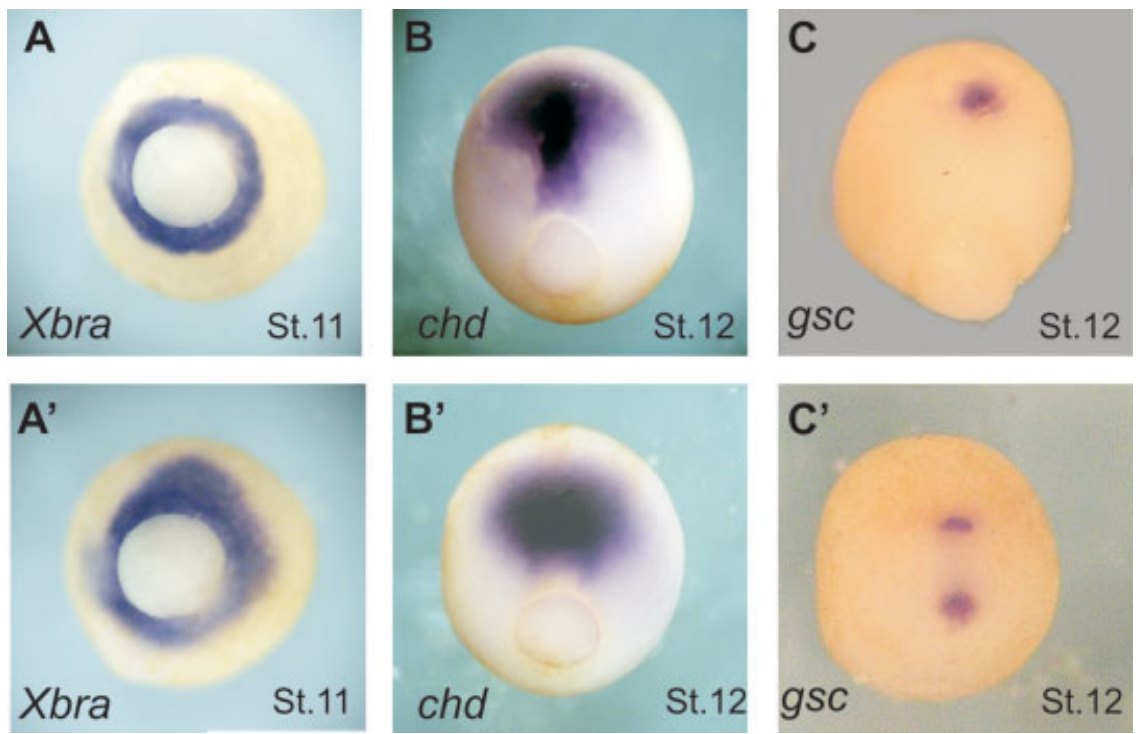

Fig. 8. synthase inhibitor), fumonisin B1 (ceramide synthase inhibitor), and $\beta$-chloroalanine (serine palmitoyltransferase inhibitor) in the early development of Xenopus laevis (Table 1). We observed that these inhibitors affected the rate of development and the gastrulation movements. Rescue experiments performed by incubation with the proper intermediate metabolite (glucosylceramide, ceramide, and sphinganine) reverted the abnormalities in embryo development caused by the glycosphingolipid blockage (Table 1). The inhibitor-treated embryos showed a morphology apparently unaffected by the experimental treatment. However, they exhibited a development rate markedly slower than that of the control.

For in vitro studies, we used the standard Keller sandwiches in which convergence and extension movements of the dorsal mesoderm occur autonomously (Doniach, 1992). The explants were cultured with the different inhibitors as indicated in Table 1. As shown in Figure 7A and B, 20 $\mu \mathrm{M}$ of PPMP solution blocked the convergence and extension movements of mesoderm. The same effects were also observed with fumonisin B1 and $\beta$-chloroalanine (data not shown). Thus, these results suggest that GSLs are necessary for proper convergenceextension movements during early development in Xenopus.

Taken all together, the results allow us to conclude that the alterations found in embryo development were caused by glycolipids depletion and that the biosynthesis of these molecules is crucial for normal gastrulation. Besides, rescue experiments show that the effects caused by the different inhibitors are specific to glycolipid functions.

Microinjection of $50 \mu \mathrm{M}$ of PPMP in a blastocoel of developing embryos affected the localization of mesodermal markers. In control embryos, Xbra

Fig. 8. Glycosphingolipids depletion affects the localization of mesodermal markers. Expression of Xbra in stage-11 control embryos (A) and PPMP-treated embryos $\left(\mathbf{A}^{\prime}\right)$. Expression of chd in stage-12 control embryos (B) and PPMP-treated embryos (B'). Expression of gsc in stage-12 control embyos (C) and PPMPtreated embryos $\left(\mathbf{C}^{\prime}\right)$. 
TABLE 1. Effects of Inhibitors of GSL Synthesis on In Vivo Development and on the Autonomous ConvergenceExtension of Keller Sandwich Explants

\begin{tabular}{|c|c|c|c|}
\hline \multirow[b]{2}{*}{ GSL inhibitor } & \multicolumn{2}{|c|}{ Effect on development $^{a}$} & \multirow{2}{*}{$\begin{array}{l}\text { Normal convergence-extension } \\
\text { movements of Keller explants } \\
(\%)\end{array}$} \\
\hline & Normal (\%) & Delayed $(\%)$ & \\
\hline Control & $92.0 \pm 2.6$ & $8.0 \pm 1.5$ & $94.3 \pm 1.5$ \\
\hline PPMP & 0 & 100.0 & 0 \\
\hline PPMP + Glucosylceramide & $90.0 \pm 1.5$ & $6.0 \pm 1.2$ & $85.0 \pm 3.50$ \\
\hline Fumonisin B1 & 0 & $98.0 \pm 2.4$ & 0 \\
\hline Fumonisin B1 + Ceramide & $89.7 \pm 3.5$ & $10.3 \pm 2.6$ & $83.3 \pm 3.8$ \\
\hline$\beta$-chloroalanine & 0 & $99.5 \pm 3.1$ & 0 \\
\hline$\beta$-chloroalanine + Sphinganine & $92.0 \pm 2.5$ & $7.0 \pm 1.6$ & $82.5 \pm 2.7$ \\
\hline Ceramide & $92.7 \pm 2.4$ & $5.0 \pm 1.6$ & $93.2 \pm 2.1$ \\
\hline Sphinganine & $90.3 \pm 2.8$ & $6.8 \pm 2.3$ & $91.3 \pm 3.1$ \\
\hline
\end{tabular}

mRNA is expressed around the blastopore and in the developing notochord (Fig. 8A) (Smith et al., 1991), chd mRNA is localized in the dorsal mesoderm of the notochord (Fig. 8B) (Sasai et al., 1994), and gsc mRNA is expressed in the mesodermal cells that will contribute to the prechordal mesoderm (head mesoderm) at the end of gastrulation (Fig. 8C) (Blumberg et al., 1991).

The distribution of Xbra mRNA at the 11 fixed PPMP treated embryos showed a wider and less regular ring around the blastopore (Fig. 8A'). Thus, we found that although this gene was expressed in GSL-depleted embryos, its expression domain was more diffuse, consistent with a reduction in morphogenetic movements that would normally compress the mesoderm to the rim of the blastopore lip.

In addition, the chd expression domain did not extend along the anterior-posterior axis, indicating a delay in the convergence of the notochord toward the dorsal midline. The notochord fails to elongate and remains near the dorsal blastoporal lip (Fig. 8B').

Interestingly, PPMP-injected embryos exhibited two domains of gsc expression at the late gastrula stage: a more anterior one and a bigger one that remains near the blastopore (Fig. $\left.8 C^{\prime}\right)$.

Although the transcription of these mesodermal molecular markers was induced at the appropriate time, the spatial expression pattern was somewhat altered, affecting the conver- gence-extension movements with a delay in mesodermal involution.

In this report, we cloned two key enzymes of the GSLs biosynthesis, assessed their expression pattern in the mesodermal and ectodermal layers in $X$. laevis embryos, and showed their role during mesodermal movements. However, further studies will be necessary to provide deeper insights into the involvement of GSLs in the complex mechanism of gastrulation.

\section{EXPERIMENTAL PROCEDURES}

\section{Identification and Isolation of cDNA Clones}

A homology search through the expressed sequence tag (EST) databases at NCBI revealed two clones originated from the Xenopus Gene Collection library (WashU Xenopus EST project, 1999; Washington University School of Medicine) and the NIBB Mochii-normalized Xenopus neurula library (accession nos. BE190123 and BJ032650, respectively). The BE190123 clone was acquired through the IMAGE Consortium/LLNL cDNA clones and the BJ032650 clone was kindly provided by Dr Naoto Ueno (NIBB, Okazaki, Japan).

Alignments of amino acid sequences and phylogenetic tree were performed using the ClustalW program (http://www. ebi.ac.uk/clustalw/index.html). The accession numbers of the aligned genes are $M$. musculus D89866, $R$. norvergicus AF047707, C. griseus AF351131, $H$. sapiens D50840, G. gallus XM424914, $X$. tropicalis NM001016133 for CGT, and $X$. laevis AJ704562, $X$. laevis AY272057, $X$. laevis AY272056, $M$. musculus NM011374, H. sapiens NM003034, and G. gallus NM205008 for $\mathrm{GD}_{3}$ synthase.

\section{Collection and Staging of Oocytes and Embryos}

Adult female Xenopus laevis specimens were stimulated with 500 IU of Human Chorionic Gonadotropin (HCG, Elea Lab.) and ovarian lobes were removed via mini-laparatomy. They were dissociated by $0.15 \%$ collagenase I (Sigma Chemical Co.) in an $\mathrm{O}-\mathrm{R} 2$ solution at $26^{\circ} \mathrm{C}$ for $20-60 \mathrm{~min}$ and the oocytes were dissected manually and staged according to Dumont (1972).

Fertilized eggs were obtained after natural single-pair mating. Males and females were injected with 400 and 500 IU of HCG, respectively. Eggs were dejellied with $2 \%$ cysteine hydrochloride $(\mathrm{pH}=7.8)$ and embryos were staged according to Nieuwkoop and Faber (1967).

\section{Expression Plasmids}

To express the carboxy-terminally epitope-tagged XLCGT with the nonapeptide epitope (YPYDVPDYA) of the viral hemagglutinin (HA) (Sells and Chernoff, 1995), a 1,247-bp DNA fragment including the Xenopus laevis cgt coding region was amplified by PCR using primer oligonucleotides 
(sense CTTGGTACCCTCGAGGCCGCCACCATGGCGGTGTTGGATCTG and antisense CTTGCGGCCGCCTAAGCGTAGTCTGGGACGTCGTATGGGTATACATCTAAGATTTCTTCC) and plasmid Bluescript SK-Xlcgt as template. The sense primer contains a $K p n I$ and $X h o I$ restriction sites and a Kozak initiation sequence (Kozak, 1987) upstream of the initiation codon for proper initiation of translation. At the antisense primer, the stop codon TAG was deleted and the last codon fused in-frame with the HA sequence. The fragment was purified, digested with the appropriate restriction enzyme, and ligated into pCEFL vector, to generate pCEFL-Xlcgt-HA. pCEFL is a derivative of pcDNA3 where the expression is driven by the human elongation factor $1 \alpha$ promoter.

The complete sequencing of the $\mathrm{Xe}$ nopus laevis gd3 synthase clone (BJ032650) reveals the lack of the $5^{\prime}$ sequence coding for the first 71 amino acids bearing the stem region, the transmembrane domain and the short cytosolic amino terminus. In order to express in ephitelial cells this short Xenopus laevis sequence of gd3 synthase (257 amino acids containing the putative catalytic domain) with the appropriated sorting signal, we performed a fusion chimera containing the first 57 amino acids of human GD $_{3}$ synthase fused to the carboxy-terminally HA epitope-tagged XLGD3 synthase from Xenopus laevis. Basically, an 824-bp DNA fragment including the Xlgd3 synthase coding region was amplified by PCR using primer oligonucleotides (sense CTTGGATCCGAGAAACCGGAGCAGCGGC and antisense CTTGCGGCCGCTTAAGCGTAGTCTGGGACGTCGTATGGGTAGTGAGGCTTTTTGGAAGAG) and plasmid Bluescript SK-gd3 synthase as template. The sense primer contains a BamHI restriction site. At the antisense primer, the stop codon TAA was deleted and the last codon fused in-frame with the HA sequence. The fragment was purified, digested with the appropriate restriction enzyme, and ligated into pEYFP-SialT-2 ${ }_{1-57}$ (Giraudo and Maccioni, 2003), replacing the yellow fluorescent protein (YFP) coding sequence, to generate the $\mathrm{pH}-\mathrm{Xlg}$ d3 synthase-HA vector.

\section{Confocal \\ Immunofluorescence Microscopy}

Cells grown on coverslips were washed twice with PBS, fixed in $4 \%$ paraformaldehyde in PBS for $15 \mathrm{~min}$ at room temperature and permeabilized with $0.1 \%$ Triton X-100/200 mM glycine in PBS for $10 \mathrm{~min}$. Then, cells were washed with PBS and incubated with PBS containing 3\% BSA for $1 \mathrm{hr}$. Coverslips were then incubated with a 1:200 dilution of specific rabbit polyclonal anti-HA antibody. After washing in PBS, the coverslips were incubated with 1:1,000 dilution of Alexa ${ }^{546}$-labeled goat anti rabbit IgG (Molecular Probes, Eugene, OR). After several washes with PBS, cells were mounted in FluorSave reagent (Calbiochem, EMD Biosciences). Confocal images were collected using a Carl Zeiss LSM5 Pascal laser-scanning confocal microscope (Carl Zeiss) equipped with an argon/helium/neon laser and a $63 \times$ Plan-Apochromat oil immersion objective and using an excitation wavelength and filter set appropriated for YFP and Alexa ${ }^{546} \mathrm{flu}$ orophores. Single confocal sections of $0.7 \mu \mathrm{m}$ were taken parallel to the coverslips ( $x y$ sections). Images were acquired and processed with the Zeiss LSM IMAGE software. Final images were compiled with Adobe Photoshop 7.0 .

\section{Electrophoresis and Western Blotting}

Proteins were resolved by electrophoresis in $10 \%$ polyacrylamide gels under reducing conditions and then transferred electrophoretically to nitrocellulose membranes for $90 \mathrm{~min}$ at $300 \mathrm{~mA}$. Protein bands in nitrocellulose membranes were visualized by Ponceau S staining. For immunoblotting, nonspecific binding sites on the nitrocellulose membrane were blocked with $5 \%$ defatted dry milk in $400 \mathrm{mM}$ $\mathrm{NaCl}, 0.05 \%$ Tween 20, 100 mM Tris$\mathrm{HCl}$, pH 7.5 buffer. Rabbit polyclonal anti-HA antibody was used at a dilution of 1:1,000 and then detected directly with an anti-rabbit IgG coupled to horseradish peroxidase and combined with the chemiluminescence detection kit (Super Signal West Pico Chemiluminescent, Pierce) and $\mathrm{Hy}$ - perfilm MP Films (Amersham Biosciences). Molecular mass was calculated based on calibrated standards (BenchMark prestained protein ladder; Invitrogen) run in every gel. Final images were compiled with Adobe Photoshop 7.0 software.

\section{Determination of XLCGT and $\mathrm{XLGD}_{3}$ synthase} Activities

XLCGT activity was assayed according to the method of Veldman et al. (2003) with slight modifications. The incubation system contained, in a final volume of $100 \mu \mathrm{l}, 20 \mu \mathrm{M} \mathrm{C} \mathrm{C}_{6}$-NBD-Ceramide (complexed with bovine serum albumin in a 1:1 molar ratio), $400 \mu \mathrm{M}$ 1-Palmitoyl-2-Oleoyl-sn-Glycero-3-Phosphocholine, $400 \mu \mathrm{M}$ UDP-glucose, $5 \mathrm{mM}$ $\mathrm{MgCl}_{2}, 5 \mathrm{mM} \mathrm{MnCl}, 1 \mathrm{mM}$ EDTA in 50 $\mathrm{mM}$ HEPES, $\mathrm{pH}$ 7.2, and cell extract (80 $\mu \mathrm{g}$ of protein from homogenates of mock transfected wild type cells or transfected with pCEFL-Xlcgt-HA vector). After $60 \mathrm{~min}$ of incubation at $37^{\circ} \mathrm{C}$, reactions were terminated by adding $500 \mu \mathrm{l}$ of chloroform/methanol (2:1, v/v). After centrifugation $(1,000 \mathrm{~g}, 5 \mathrm{~min})$, the lower phases were dried under nitrogen and subjected to thin layer chromatographic (TLC) by using chloroform/ methanol/water $(65: 25: 4, \mathrm{v} / \mathrm{v})$ as the mobile phase. $\mathrm{C}_{6}-\mathrm{NBD}$ lipids were visualized in the TLC by UV illumination.

$\mathrm{XLGD}_{3}$ synthase activity was determined essentially as described (Daniotti et al., 1994). Homogenates of wild type $\mathrm{CHO}-\mathrm{K} 1$ cells or transfected with $\mathrm{pH}-X l g d 3$ synthase-HA vector were used as an enzyme source for the determination of XLGD3 synthase activity. The incubation system contained, in a final volume of $30 \mu \mathrm{l}, 100$ $\mu \mathrm{M}$ GM3, $100 \mu \mathrm{M}$ CMP- $\left[{ }^{3} \mathrm{H}\right] \mathrm{NeuAc}$ (250,000 cpm), $20 \mathrm{mM} \mathrm{MnCl}_{2}, 1 \mathrm{mM}$ $\mathrm{MgCl}_{2}, 20 \mu \mathrm{g}$ of Triton CF54/Tween 80 $(2: 1 \mathrm{w} / \mathrm{w}), 100 \mathrm{mM}$ sodium cacodylate$\mathrm{HCl}$ buffer ( $\mathrm{pH}$ 6.5), and cell extract (40 $\mu \mathrm{g}$ of protein). Incubations were performed at $37^{\circ} \mathrm{C}$ for $90 \mathrm{~min}$. Samples without exogenous acceptor were used to correct the incorporation into endogenous acceptors. Reactions were stopped with $1 \mathrm{ml}$ of $5 \%$ (w/v) trichloroacetic acid $/ 0.5 \%$ phosphotungstic acid (TCA/PTA). Precipitates were collected by centrifugation, washed twice with 1 $\mathrm{ml}$ of TCA/PTA solution, and extracted 
with $0.5 \mathrm{ml}$ of chloroform/methanol (2:1 $\mathrm{v} / \mathrm{v})$. Lipids extracts were evaporated in a vial and then dissolved in $50 \mu \mu l$ of $10 \%$ SDS; after addition of $2 \mathrm{ml}$ scintillation cocktail, its radioactivity was determined.

\section{RNA Isolation and RT-PCR Analysis}

Total RNA was isolated from oocytes and embryos by the guanidine thiocyanato/phenol/chloroform method (Chomczynski and Sacchi, 1987) and cDNAs were synthesized by using reverse transcriptase (Roche Biochemicals) and oligo(dT) primer.

The primers designed for this study were Xlcgt: 5'-GCCATTTTTGGCTGTGTCTT-3' (upstream) and 5'-CACTAGGATATTTGCCAAGC-3' (downstream) at an annealing temperature of $58^{\circ} \mathrm{C}$; Xlgd3 synthase: 5'-ACTAAAGCCAATACTGCGCTG-3' (upstream) and $\quad 5^{\prime}$-ATAGTGATGGCTGATGTGCC-3' (downstream) at an annealing temperature of $64^{\circ} \mathrm{C}$. For amplification of Ornithine decarboxylase (ODC), primers 5'-CAGCTAGCTGTGGTGTGG-3' (upstream) and 5' -CAACATGGAAACTCACACC-3' (downstream) (Agius et al., 2000) were used. $\mathrm{H}_{4}$ primers sequences were obtained from the website of Dr. Edward M. de Robertis (http:/www.hhmi.ucla.edu/derobertis/ protocol_page/oligos.PDF). PCR amplification with these primers was performed over 28 cycles and the PCR products were analyzed on $1.5 \%$ agarose gels. As a control, PCR was performed with RNA that had not been reverse transcribed.

\section{Whole-Mount In Situ Hybridization}

Antisense probes for Xlcgt and Xlgd3 synthase (digested with EcoRI from pBluescript vector) containing digoxigenin-11-UTP (Roche Biochemicals) were prepared by in vitro transcription. Specimens were prepared, hybridized, and stained according to Harland (1991) with the modifications described by Mancilla and Mayor (1998). Basically, RNase treatment was omitted and the antibody was incubated and washed in maleic acid buffer (100 mM maleic acid, Sigma; $150 \mathrm{mM} \mathrm{NaCl}, \mathrm{pH}=7.5$ ) containing $2 \%$ of Boehringer Mannheim blocking reagent. For histological examination, whole-mount processed embryos were dehydrated, embedded in paraplast, and cut into $15-\mu \mathrm{m}$ sections. Linearized plasmid from Xbra (XhoI/SP6), gsc (EcoRI/T7), and chd (EcoRI/T7) were used to generate digoxigenin-11UTP-labeled antisense probes from the polymerases indicated. Xbra cDNA was kindly provided by Ali Hemmati-Brivanlou and gsc and $c h d$ cDNAs by Edward M. de Robertis.

\section{Ganglioside Biosynthesis Inhibition and Rescue Experiments}

To monitor the in vivo effects of the inhibitors of glycosphingolipids biosynthesis on embryonic development, different groups of blastulae embryos were cultured for $24 \mathrm{hr}$ in 10\% NAM solution with $20 \mu \mathrm{M}$ PPMP(D-threo1-phenyl-2-palmitoyl-3-morpholino-1propanol), $20 \mu \mathrm{M}$ fumonisin $\mathrm{B} 1$, or 20 $\mu \mathrm{M} \beta$-chloroalanine (Sigma Chemicals); others were treated with each inhibitor plus the corresponding intermediate metabolite (50 $\mu \mathrm{M}$ glucosylceramide, ceramide, or sphinganine) and the control group was incubated in $10 \%$ NAM solution.

To facilitate the penetration of the different drugs into the blastocoel, the vitelline envelope was removed and small slits made on the animal pole of the blastulae. The same procedure was carried out in the control embryos with saline solution.

In order to analyze the effect of the inhibitors on the autonomous convergence-extension of mesoderm, the in vitro assays were made with Keller sandwich explants. Different groups were cultured for $24 \mathrm{hr}$ in $10 \%$ NAM solution with $20 \mu \mathrm{M}$ PPMP, $20 \mu \mathrm{M}$ fumonisin $\mathrm{B} 1$, or $20 \mu \mathrm{M} \beta$-chloroalanine; others were treated with each inhibitor plus the corresponding intermediate metabolite (50 $\mu \mathrm{M}$ glucosylceramide, ceramide, or sphinganine) and the control group was incubated in $10 \%$ NAM solution.

\section{Microinjection}

Dejellied embryos were placed in $10 \%$ NAM containing $5 \%$ Ficoll and stage- 9 embryos were injected in blastocoel with $50 \mu \mathrm{M}$ of PPMP. The embryos were cultured in $10 \%$ NAM until the sibling batch reached the 12.5 or 13 stage, when they were processed by whole-mount in situ hybridization to visualize mesodermal markers expression (Xbra, gsc, and $c h d)$.

\section{Convergence-Extension Assay}

Explants were made at stage 10.5 by cutting out a rectangle of circumblastoporal tissue as described by Doniach (1992). Sandwich explants were made by putting two of these rectangles together with their inner surfaces apposed and incubating them with or without PPMP solutions $(20 \mu \mathrm{M})$ until neurulation took place in the sibling batch.

\section{ACKNOWLEDGMENTS}

We thank Naoto Ueno for the EST BJ032650 clone. We also thank Ali Hemmati-Brivanlou (Xbra) and Edward M. de Robertis ( $g s c$ and $c h d$ ) for gifts of plasmids. This research was supported by Consejo Nacional de Investigaciones Científicas y Técnicas (CONICET) and CIUNT grants to S.S.S and grants from Secretaría de Ciencia y Tecnologíía, Universidad Nacional de Córdoba; CONICET and Agencia Nacional de Promoción Científica y Tecnológica (FONCYT), Argentina, to J.L.D. We thank Mrs. Virginia Méndez for proofreading.

\section{REFERENCES}

Agius E, Oelgeschlager M, Wessely O, Kemp C, De Robertis EM. 2000. Endodermal Nodal-related signals and mesoderm induction in Xenopus. Development 127:1173-1183.

Allende ML, Proia RL. 2002. Lubricating cell signaling pathways with gangliosides. Curr Opin Struct Biol 12:587-592.

Aybar MJ, Fuentes A, Sanchez SS. 2000a. Inhibition of the synthesis of glycosphingolipid by a ceramide analogue (PPMP) in the gastrulation of Bufo arenarum. Zygote 8:159-169.

Aybar MJ, Genta SB, Sanchez Riera AN, Sanchez SS. 2000b. Participation of the GM1 ganglioside in the gastrulation of anuran amphibian Bufo arenarum. J Exp Zool 286:457-472.

Basu S, Kaufman B, Roseman S. 1968. Enzymatic synthesis of ceramide-glucose and ceramide-lactose by glycosyltransferases from embryonic chicken brain. J Biol Chem 243:5802-5804.

Blumberg B. Wright CV. De Robertis EM. Cho KW. 1991. Organizer-specific ho- 
meobox genes in Xenopus laevis embryos. Science 253:194-196.

Campbell JA, Davies GJ, Bulone V, Henrissat B. 1997. A classification of nucleotide-diphospho-sugar glycosyltransferases based on amino acid sequence similarities. Biochem J 326:929-939. Erratum in: Biochem J 1998 Feb 1;329:719.

Chomczynski P, Sacchi N. 1987. Singlestep method of RNA isolation by acid guanidinium thiocyanate-phenol-chloroform extraction. Anal Biochem 162:6-9.

Choo YK, Ichikawa S, Hirabayashi Y. 2001. Developmental patterns of ceramide glucosyltransferase (GlcT-1) expression in the mouse: in situ hybridization using DIG-labeled RNA probes. Mol Cells 11:346-351.

Coste H, Martel MB and Got R. 1986. Topology of glucosylceramide synthesis in Golgi membranes from porcine submaxillary glands. Biochim Biophys Acta 858:6-12.

Daniotti JL, Landa CA, and Maccioni HJ. 1994. Regulation of ganglioside composition and synthesis is different in developing chick retinal pigment epithelium and neural retina. J Neurochem 62:1131-1136.

Degroote S, Wolthoorn J, van Meer G. 2004. The cell biology of glycosphingolipids. Semin Cell Dev Biol 15:375-387.

Doniach T. 1992. Induction of anteroposterior neural pattern in Xenopus by planar signals. Dev Suppl 183-93.

Dumont JN. 1972. Oogenesis in Xenopus laevis (Daudin). I. Stages of oocyte development in laboratory maintained animals. J Morphol 136:153-179.

Durieux I, Martel MB, Got R. 1990. Solubilization of UDP glucose-ceramide glucosyltransferase from the Golgi apparatus. Biochim Biophys Acta 1024:263-266.

Giraudo CG, Maccioni HJF. 2003 Ganglioside glycosyltransferases organize in distinct multienzyme complexes in CHO-K1 cells. J Biol Chem 278:40262-40271.

Gornati R, Rizzo AM, Tong XW, Berra B, Bernardini G. 1995. Glycolipid patterns during Xenopus embryo development. Cell Biol Int 19:183-189.

Gornati R, Basu S, Bernardini G, Rizzo AM, Rossi F, Berra B. 1997. Activities of glycolipid glycosyltransferases and sialidases during the early development of Xenopus laevis. Mol Cell Biochem 166:117-124.

Hakomori S. 1990. Bifunctional role of glycosphingolipids. Modulators for transmembrane signaling and mediators for cellular interactions. J Biol Chem 265: 18713-18716.

Hakomori S. 2004. Carbohydrate-to-carbohydrate interaction, through glycosynapse, as a basis of cell recognition and membrane organization. Glycoconj J 21: 125-137.

Hakomori S, Handa K. 2003. Interaction of glycosphingolipids with signal transducers and membrane proteins in glycosphingolipid-enriched microdomains. Methods Enzymol 363:191-207.

Harduin-Lepers A, Mollicone R, Delannoy P, Oriol R. 2005. The animal sialyltransferases and sialyltransferase-related genes: a phylogenetic approach. Glycobiology 15:805-817.
Harland RM. 1991. In situ hybridization: an improved whole-mount method for Xenopus embryos. Methods Cell Biol 36: 685-695.

Hellsten U, Khokha MK, Grammer TC, Harland RM, Richardson P, Rokhsar DS. 2007. Accelerated gene evolution and subfunctionalization in the pseudotetraploid frog Xenopus laevis. BMC Biol 5:31.

Hidari K, Itonori S, Sanai Y, Ohashi M, Kasama T, Nagai Y. 1991. Isolation and characterization of a monosialosylgangliopentaosyl ceramide from Xenopus laevis oocyte. J Biochem 110:412-416.

Hidari KI, Ichikawa S, Fujita T, Sakiyama H, Hirabayashi Y. 1996. Complete removal of sphingolipids from the plasma membrane disrupts cell to substratum adhesion of mouse melanoma cells. J Biol Chem 271:14636-14641.

Ichikawa S, Sakiyama H, Suzuki G, Hidari KI, Hirabayashi Y. 1996. Expression cloning of a cDNA for human ceramide glucosyltransferase that catalyzes the first glycosylation step of glycosphingolipid synthesis. Proc Natl Acad Sci USA 93:12654.

Ichikawa S, Ozawa K, Hirabayashi Y. 1998. Molecular cloning and expression of mouse ceramide glucosyltransferase. Biochem Mol Biol Int 44:1193-1202.

Inoue M, Fujii Y, Furukawa K, Okada M, Okumura K, Hayakawa T, Furukawa K, Sugiura Y. 2002. Refractory skin injury in complex knock-out mice expressing only the GM3 ganglioside. J Biol Chem 277:29881-29888.

Jeckel D, Karrenbauer A, Burger KN, van Meer G, Wieland F. 1992. Glucosylceramide is synthesized at the cytosolic surface of various Golgi subfractions J Cell Biol 117:259-267.

Ji MY, Lee YC, Kim KS, Cho JW, Jung KY, Kim CH, Choo YK. 1999. Developmental patterns of GalBeta1,3(4)GlcNAc alpha2,3-sialyltransferase (ST3Gal III) expression in the mouse: in situ hybridization using DIG-labeled RNA probes. Arch Pharm Res 22:243-248.

Kapitonov D, Yu RK. 1999. Conserved domains of glycosyltransferases. Glycobiology 9:961-978.

Kawai H, Allende ML, Wada R, Kono M, Sango K, Deng C, Miyakawa T, Crawley JN, Werth N, Bierfreund U, Sandhoff K, Proia RL. 2001. Mice expressing only monosialoganglioside GM3 exhibit lethal audiogenic seizures. J Biol Chem 276: 6885-6888.

Kohyama-Koganeya A, Sasamura T, Oshima E, Suzuki E, Nishihara S, Ueda R, Hirabayashi Y. 2004. Drosophila glucosylceramide synthase: a negative regulator of cell death mediated by proapoptotic factors. J Biol Chem 279:35995-36002.

Kolter T, Proia RL, Sandhoff K. 2002. Combinatorial ganglioside biosynthesis. J Biol Chem 277:25859-25862.

Kozak M. 1987. An analysis of 59-noncoding sequences from 699 vertebrate messenger RNAs. Nucleic Acids Res 15:81258148.

Kubo H, Kotani M, Ozawa H, Kawashima I, Tai T, Suzuki A. 1995. Differential dis- tribution of ganglioside GM1 and sulfatide during the development of Xenopus embryos. Dev Growth Differ 37:243-255.

Mancilla A, Mayor R. 1996. Neural crest formation in Xenopus laevis: mechanisms of Xslug induction. Dev Biol 177: 580-589.

Marks DL, Dominguez M, Wu K, Pagano RE. 2001. Identification of active site residues in glucosylceramide synthase. A nucleotide-binding catalytic motif conserved with processive beta-glycosyltransferases. J Biol Chem 276:26492-26498.

Martina JA, Daniotti JL and Maccioni HJF. 1998. Influence of N-glycosylation and N-glycan trimming on the activity and intracellular traffic of GD3 synthase (ST8Sia I). J Biol Chem 273:3725-3731.

Nieuwkoop PD, Faber J. 1967. Normal table of Xenopus laevis. Amsterdam: Daudin, North Holland.

Okada M, Itoh Mi M, Haraguchi M, Okajima T, Inoue M, Oishi $\mathrm{H}$, Matsuda $\mathrm{Y}$, Iwamoto T, Kawano T, Fukumoto $\mathrm{S}$, Miyazaki H, Furukawa K, Aizawa S, Furukawa K. 2002. b-series Ganglioside deficiency exhibits no definite changes in the neurogenesis and the sensitivity to Fas-mediated apoptosis but impairs regeneration of the lesioned hypoglossal nerve. J Biol Chem 277:1633-1636.

Rimoldi S, Papis E, Bernardini G, Prati M, Gornati R. 2007. Molecular cloning and expression of alpha 2,8-sialyltransferase (ST8Sia I, GD3 Synthase) in Xenopus. Mol Cell Biochem 301:143-153.

Sasai Y. Lu B. Steinbeisser H. Geissert D. Gont LK. De Robertis EM. 1994. Xenopus chordin: a novel dorsalizing factor activated by organizer-specific homeobox genes. Cell 79:779-790.

Sells MA, Chernoff J. 1995. Epitope-tag vectors for eukaryotic protein production. Gene 152:187-189.

Simons K, Toomre D. 2000. Lipid rafts and signal transduction. Nat Rev Mol Cell Biol 1:31-39. Erratum in: Nat Rev Mol Cell Biol 2001 2:216.

Smith JC, Price BM, Green JB, Weigel D, Herrmann BG. 1991. Expression of a Xenopus homolog of Brachyury (T) is an immediate-early response to mesoderm induction. Cell 67:79-87.

Veldman RJ, Mita A, Cuvillier O, Garcia V, Klappe K, Medin JA, Campbell JD, Carpentier S, Kok JW, Levade T. 2003. The absence of functional glucosylceramide synthase does not sensitize melanoma cells for anticancer drugs. FASEB J 17: 1144-1146.

Wu K, Marks DL, Watanabe R, Paul P, Rajan N, Pagano RE. 1999. Histidine193 of rat glucosylceramide synthase resides in a UDP-glucose- and inhibitor (D-threo-1-phenyl-2-decanoylamino-3-morpholinopropan-1-ol)-binding region: a biochemical and mutational study. Biochem J 341:395-400.

Yamashita T, Wada R, Sasaki T, Deng C, Bierfreund U, Sandhoff K, Proia RL. 1999. A vital role for glycosphingolipid synthesis during development and differentiation. Proc Natl Acad Sci USA 96: 9142-9147. 